\title{
Why are Birth Defects Surveillance Programs Important?
}

\author{
Débora Gusmão Melo ${ }^{1 *}$, Maria Teresa Vieira Sanseverino ${ }^{2,3}$, \\ Thanyse de Oliveira Schmalfuss ${ }^{4}$ and Mariela Larrandaburu ${ }^{5}$ \\ ${ }^{1}$ Department of Medicine, Federal University of São Carlos (UFSCar), São Carlos, Brazil, ${ }^{2}$ School of Medicine, Pontifical \\ Catholic University of Rio Grande do Sul, Porto Alegre, Brazil, ${ }^{3}$ Medical Genetics Service, Clinical Hospital of Porto Alegre, \\ Porto Alegre, Brazil, ${ }^{4}$ School of Medicine, Federal University of Rio Grande do Sul (UFRGS), Porto Alegre, Brazil, ${ }^{5}$ Disability \\ and Rehabilitation Program, Ministry of Public Health of Uruguay, Montevideo, Uruguay
}

Keywords: birth defects, congenital anomalies, public health surveillance, epidemiological monitoring, registries, teratogens, newborn screening

\section{INTRODUCTION}

Public health surveillance is described as the ongoing, systematic collection, analysis, and interpretation of health-related data essential to planning, implementation, and evaluation of public health policies strongly integrated with the opportune dissemination of these data to those responsible for prevention and control (1). Specifically, concerning birth defects or congenital anomalies, it is important to highlight the British Columbia Health Surveillance Registry, which has

OPEN ACCESS

Edited by:

Satinder Aneja,

Sharda University, India

Reviewed by:

Kristin Conway,

The University of lowa, United States

Brian Lowry

Alberta Children's Hospital, Canada

*Correspondence:

Débora Gusmão Melo

dgmelo@ufscar.br

Specialty section:

This article was submitted to

Children and Health,

a section of the journal

Frontiers in Public Health

Received: 20 August 2021 Accepted: 08 October 2021 Published: 02 November 2021

Citation:

Melo DG, Sanseverino MTV Schmalfuss TO and Larrandaburu $M$ (2021) Why are Birth Defects

Surveillance Programs Important? Front. Public Health 9:753342.

doi: 10.3389/fpubh.2021.753342 recorded cases of birth defects, genetic diseases, and chronic disabilities since 1952 (2), although the ascertainment sources and reporting procedures for birth defects have been more consistent since 1966 (3). Forsooth, public health surveillance of birth defects was driven by the thalidomide epidemic (4), which disclosed the need to establish systems that could identify teratogenic agents. More than 50 years later, the Zika epidemic reiterated this requirement $(5,6)$.

Congenital anomalies, defined as abnormalities of body structure or function that have a prenatal origin and are evident or not at birth, are a diverse group that can be caused by chromosomal disorders, single-gene defects, multifactorial inheritance, environmental teratogens or micronutrient malnutrition, and maternal illness (7). In 2004, an estimated 260,000 deaths globally were attributable to congenital anomalies. In 2010, the 63rd World Health Assembly adopted a resolution urging countries to develop and strengthen congenital anomalies surveillance systems (8).

Birth defects surveillance programs can usually be classified into two main types: populationbased, which investigates birth defects among the whole population residing in a delimited geographic area, or hospital-based, which investigates birth defects in selected hospitals, maternity hospitals, or facilities, and which coverage corresponds to births or hospital admissions in these places (9). Concerning cases detection, it can be further divided into active case-finding, which requires systematic screening and clinical evaluation of children; passive case-finding, when affected individuals have access to health facilities and then are recognized; or a hybrid case-finding system (10). In addition to population coverage and case-finding, the design and data gathering on birth defects can be different among several surveillance programs mainly regarding the case definition, age of inclusion, inclusion or absence of data from prenatal diagnosis and elective termination of pregnancy for fetal anomaly (ETOPFA), congenital anomalies description, and coding systems (7). Although the definition of birth defects includes both structural and functional anomalies, birth defects surveillance programs often monitor major structural birth defects and sometimes minor structural birth defects, too (11). The detection of functional anomalies as inborn errors of metabolism and blood disorders is frequently performed by neonatal screening programs 
(8). In any case, the most significant aspect of a public health surveillance program is how the data collected will be used to promote the health of the people and the population (12).

In this opinion article, we discuss why birth defects surveillance programs are important and how they can track, assess, and improve the management of congenital anomalies at both the individual and collective levels, which makes a strong argument for continuing to monitor congenital anomalies around the world.

\section{PURPOSES AND OBJECTIVES OF BIRTH DEFECTS SURVEILLANCE PROGRAMS}

\section{Epidemiological Purpose}

A regular purpose of birth defects surveillance programs is to provide epidemiologic data. This surveillance can point out baseline rates and monitor the trends in birth defects occurrence. Monitoring reveals quantitative estimates of the magnitude of the disease. In this way, surveillance programs can identify clusters of congenital defects and serve as an early detection system for unexpected increases in their frequency resulting from the introduction of new and old teratogens in the population (12-14). For example, this was how misoprostol and the Zika virus were related to a cluster of birth defects and identified as teratogens initially $(15,16)$. This is also how the cases of fetal rubella syndrome have been monitored and controlled in many regions around the world until today $(17,18)$.

\section{Planning and Prevention Purposes}

Another purpose of birth defects surveillance programs is planning and prevention. Data obtained from surveillance can serve to plan promotion and prevention strategies and guide public policies (12). The case of folic acid food fortification to prevent neural tube defects demonstrates that. The surveillance data allow for the comparison and monitoring of the prevalence of neural tube defects before, during, and after the implementation of folic acid fortification of staple foods. In different places, these data have been supported the role of folic acid fortification in the decline of neural tube defects birth prevalence, therefore allowing evaluation of the effectiveness of the acid folic fortification as a preventive action (19-21).

Still from the perspective of prevention, data from birth defects surveillance programs can be used to support collective health education actions. Some regions report the prevalence of fetal alcohol syndrome using data from their birth defects surveillance programs and eventually, they look for an association between alcohol consumption during pregnancy and birth defects $(12,22,23)$. These strategies allow developing education and primary prevention actions among women of childbearing age and also identifying children exposed to alcohol in the uterus that could require appropriate intervention services. Additionally, there must be successful surveillance programs to evaluate the effectiveness of prevention efforts in these situations $(12,23)$. It may be worth mentioning that difficulties in accurately recognizing cases of alcohol-induced birth defects have led to the emergence of specific surveillance systems for fetal alcohol syndrome, which normally screen children older than is typical in general birth defects surveillance (24-26).

\section{Referral to Professionals and Health Care Services}

Information from birth defects surveillance programs can be used also in a familial or individual-level approach to managing the special needs of children and their families in a more suitable way. Surveillance program data may serve to refer newly identified children with birth defects for services that include specialized health care, educational and early intervention programs, and genetic counseling. Thus, affected children and their families can be connected with appropriate services promptly, contributing to establish referral networks related to medical services, community programs, and social support (27, 28). Additionally, this can facilitate access for patients with birth defects and genetic rare diseases to clinical and epidemiologic research $(13,29,30)$. Furthermore, data can also be applied to evaluate the utilization of offered services (12).

Correctly predicting the request for several interdisciplinary clinics, social and educational services is crucial for children with birth defects. Based on congenital anomalies prevalence, birth defects surveillance programs can help to estimate future service demands, allowing for capacity strengthening to guarantee that necessary resources will be accessible and those appropriate professionals will be available to provide the services (31). Forecasting demand for services can be useful both in general terms and can guide the structuring of comprehensive care for people with specific congenital anomalies. To give an instance, information from birth defects surveillance programs has been provided data for planning services for children with orofacial clefts at various locations (32-34).

\section{Provide a Basis for Clinical Research and Human Resource Training}

Finally, birth defects surveillance programs can provide data for clinical research, follow-up studies of long-term effects, and studies of economic impact, as well as provide human resource training in the surveillance and research of congenital anomalies $(12,13)$.

It allows carrying out population-based clinical research, which is particularly important regarding rare diseases for which big data commonly are not available (35). The development of epidemiological studies that seek to identify the patterns and causes of congenital abnormalities contributes to more adequate prevention strategies for each country. It can support research on interventions for people with birth defects and measure the outcomes and impact of these interventions on family dynamics and the quality of life of individuals. It also contributes to advancing current knowledge about diagnostics, pathophysiology, and treatment through basic research $(13,36)$. For instance, although thalidomide embryopathy is well-known, its pathophysiology is still not totally understood. The recent cases of children with thalidomide embryopathy identified in Brazil (37) have contributed to the development of studies that try to elucidate pathophysiologic mechanisms of this teratogen, 
allowing a better understanding of the susceptibility to phenotype and the development of pharmacogenomic strategies (38).

Providing education and training both in the surveillance and research of birth defects is an essential goal of the congenital anomalies' surveillance programs. For that, there is a collection of freely available courses covering surveillance methodology, coding, implementation of programs in low-resource settings, and developing strategies to prevent birth defects (39-42).

\section{THE BENEFIT OF BIRTH DEFECTS SURVEILLANCE TO OTHER HEALTH-RELATED PROGRAMS}

Birth defects surveillance data are customarily linked to vital records, like birth certificates, and thus demographic characteristics and parental survey data, such as ethnicity and education (43). It is possible to link records from birth defects surveillance with datasets from other surveillance health-related programs. These include, for example, newborn screening, early interventions, hospitalizations, and death certificates (12, 43-46).

Because of birth defects impact on child morbidity and mortality, there are many precedents of childhood mortality analyses that incorporate birth defects registry data, providing an effective mechanism for monitoring the survival and mortality risks of children with selected major birth defects, such as congenital heart disease (47), esophageal atresia (48), spina bifida (49), diaphragmatic hernia (50), and omphalocele (51).

The potential to link records and consolidate information from different databases contributes to assorted public health applications of surveillance data. To illustrate, Sales Luiz Vianna et al. investigated data from the Brazilian birth defects surveillance system, defined a more likely thalidomide embryopathy phenotype, and linked that with surveillance data from the National Leprosy Program. They showed a correlation between thalidomide prescription and that specific phenotype, reinforcing that thalidomide embryopathy should be better monitored in countries where this medication is available (37).

\section{CHALLENGES FOR BIRTH DEFECTS SURVEILLANCE PROGRAMS}

Collaborative efforts must be made to standardize data collection, coding, and analysis, increasing the utility of birth defects programs globally $(13,14,45)$. Promoting international cooperation is also the main question. International collaborative networks are important for improving birth defects surveillance because they contribute to the understanding of the global epidemiological setting of these disorders, besides strengthening surveillance initiatives in unassisted regions $(9,13,52)$. Recent literature review about the subject identified six international congenital anomaly surveillance collaboration networks: Estudio Colaborativo Latino Americano de Malformaciones Congénitas (ECLAMC), International Clearinghouse for Birth Defects Surveillance and Research (ICBDSR), European Surveillance of Congenital Anomalies (EUROCAT), British and Irish Network of Congenital Anomaly Researchers (BINOCAR), South-East Asia
Region's Newborn and Birth Defects Database (SEAR-NBBD), and Red Latinoamericana de Malformaciones Congénitas (ReLAMC) (9).

There is a need for actions to expand birth defects surveillance, prevention, and care in low and middle-income countries, sceneries often associated with poor maternal nutrition and/or exposure to infection and other teratogens, and scarce family planning programs. Particularly in conditions of limited financial resources, birth defects surveillance programs can provide an accurate estimate of the burden of congenital anomalies, which can be used to advocate for prevention and care and to also evaluate the impact of the public established actions $(36,53,54)$. But even consolidated birth defect surveillance programs in the USA, Canada, and Europe suffer financial constraints that can impair their functioning. It is interesting to note that healthcare systems are sometimes reorganized to reduce costs without the procedures and data of birth defects surveillance programs being considered (55).

Additionally, some researchers advocate expanding surveillance systems to ensure that functional or developmental defects are also counted along with structural birth defects (36). The National Registry of Congenital Defects and Rare Diseases-RNDCER of Uruguay, for example, have included the mandatory notification of neonatal screening pathologies (56). Newborn screening is one of the most widely distributed population screening programs worldwide (57). Despite the discrepancy in neonatal screening programs across countries since the late 1990s, tandem mass spectrometry has been increasingly introduced into newborn screening enabling the identification of more than 30 inherited metabolic diseases, some of them with effective treatments $(57,58)$. However, newborn screening is useful not only for the detection of inborn errors of metabolism but also for endocrine, hematologic, immune, cardiac, and pulmonary diseases $(58,59)$, as well as sensory defects such as deafness (60) and visual problems (61). There is extensive discussion in the literature about the cost-effectiveness of ultrasound screening programs for birth defects $(62,63)$, although some congenital birth defects such as developmental dysplasia of the hip and congenital heart diseases are better identified through imaging tests (64-66). Besides that, other tools are helpful in neonatal screening such as pulse oximetry in the case of heart defects (67), the red reflex test in the case of visual problems (68), and otoacoustic emissions or auditory brainstem response in the case of hearing assessment (69). Improving the coverage of newborn screening to achieve everyone and ensuring the inclusion of diseases that can be early treated to promote secondary prevention are great challenges. That will require not only the availability of metabolic and imaging tests, but also the provision of appropriate treatment and longitudinal follow-up of children's development. This last is very important to measure the impact actions of the newborn screening program.

Recently, models of triple surveillance have been proposed to support and accelerate birth defect prevention. The concept of triple surveillance is complex and implies including and integrating the three basic domains of the causal chain, that is, from cause to disease occurrence and health outcomes. Botto 
and Mastroiacovo give some examples of triple surveillance for selected congenital conditions. For instance, specifically for neural tube defects, they recommend surveillance folate deficiency through blood tests, assessment of neural tube defects prevalence and lifelong disability (70).

One last point that deserves to be highlighted is that although evidence regarding Covid-19 does not suggest increased risks for congenital anomalies (71), just like many other sectors of public health and medicine, birth defects surveillance programs may be faced with organizational and methodological barriers because of the Covid-19 pandemic, requiring to reorganize and respond to a changing panorama (72).

\section{CONCLUSIONS}

In summary, the information collected through birth defects surveillance programs is used to produce prevalence data, recognize risk factors, foster the development of research in the

\section{REFERENCES}

1. Thacker SB, Birkhead GS. Surveillance. In: Gregg MB, editor. Field Epidemiology. Oxford: Oxford University Press (2008). p. 38-66. doi: 10.1093/acprof:oso/9780195313802.003.0003

2. Miller JR. Description of a handicapped population: the British Columbia Health Surveillance Registry. Birth Defects Orig Artic Ser. (1976) 12:1-11.

3. Baird PA. Measuring birth defects and handicapping disorders in the population: the British Columbia Health Surveillance Registry. CMAJ. (1987) 136:109-11.

4. Lenz W, Knapp K. Thalidomide embryopathy. Arch Environ Health. (1962) 5:100-5. doi: 10.1080/00039896.1962.10663250

5. França GV, Schuler-Faccini L, Oliveira WK, Henriques CM, Carmo EH, Pedi VD, et al. Congenital Zika virus syndrome in Brazil: a case series of the first 1501 livebirths with complete investigation. Lancet. (2016) 388:891-7. doi: 10.1016/S0140-6736(16)30902-3

6. Larrandaburu M, Luiz Vianna FS, Anjos da Silva A, Nacul L, Vieira Sanseverino MT, Schuler-Faccini L. Zika virus infection and congenital anomalies in the Americas: opportunities for regional action. Rev Panam Salud Publica. (2017) 41:e174. doi: 10.26633/RPSP.2017.174

7. WHO, CDC, ICBDSR. Birth Defects Surveillance: A Manual for Programme Managers. Geneva: World Health Organization (2020). p. 248. Available online at: https://www.who.int/publications/i/item/9789240015395 (accessed July 19, 2021).

8. WHO, World Health Assembly, 63. Birth Defects: Report by the Secretariat. World Health Organization (2010). p. 7. Available online at: https://apps.who. int/iris/handle/10665/2378 (accessed July 19, 2021).

9. Cardoso-Dos-Santos AC, Magalhães VS, Medeiros-de-Souza AC, Bremm JM, Alves RFS, Araujo VEM, et al. International collaboration networks for the surveillance of congenital anomalies: a narrative review. Epidemiol Serv Saude. (2020) 29:e2020093. doi: 10.5123/s1679-49742020000400003

10. Pan American Health Organization and the World Bank. Present and Future of Birth Defects Surveillance in the Americas. Washington, DC: PAHO, World Bank (2019). p. 76. Available online at: https://iris.paho.org/handle/10665.2/ 51899 (accessed September 23, 2021).

11. Groisman B, Liascovich R, Bidondo MP, Barbero P, Duarte S, Tellechea AL, et al. Birth defects surveillance: experiences in Argentina and Colombia. $J$ Community Genet. (2019) 10:385-93. doi: 10.1007/s12687-018-00403-6

12. National Birth Defects Prevention Network. Guidelines for Conducting Birth Defects Surveillance. Atlanta, GA: National Birth Defects Prevention Network (2004). p. 855. Available online at: https://www.nbdpn.org/docs/Full_SGSC_ Manual_2021MARCH12.pdf (accessed September 23, 2021). area, develop prevention strategies, plan for services, and referral of affected children to medical, educational, and social services. Further, there is a global tendency for congenital anomalies surveillance programs around the world to work in networks, which gives more strength to their data and conclusions. Therefore, birth defects surveillance programs constitute an important data source to guide public health actions worldwide.

\section{AUTHOR CONTRIBUTIONS}

DM conceived and drafted the manuscript. MS, TS, and ML helped to design the manuscript and critically revised it. All authors read and approved the final manuscript.

\section{FUNDING}

This research did not receive any specific grant from funding agencies in the public, commercial, or not-for-profit sectors.

13. Bermejo-Sánchez E, Botto LD, Feldkamp ML, Groisman B, Mastroiacovo P. Value of sharing and networking among birth defects surveillance programs: an ICBDSR perspective. J Community Genet. (2018) 9:411-5. doi: $10.1007 / \mathrm{s} 12687-018-0387-\mathrm{z}$

14. Mburia-Mwalili A, Yang W. Birth defects surveillance in the united states: challenges and implications of international classification of diseases, tenth revision, clinical modification implementation. Int Sch Res Notices. (2014) 2014:212874. doi: 10.1155/2014/212874

15. Orioli IM, Castilla EE. Epidemiological assessment of misoprostol teratogenicity. BJOG. (2000) 107:519-23. doi: 10.1111/j.1471-0528. 2000.tb13272.x

16. Kleber de Oliveira W, Cortez-Escalante J, de Oliveira WT, do Carmo GM, Henriques CM, Coelho GE, et al. Increase in reported prevalence of microcephaly in infants born to women living in areas with confirmed Zika virus transmission during the first trimester of pregnancy - Brazil, 2015. MMWR Morb Mortal Wkly Rep. (2016) 65:242-7. doi: 10.15585/ mmwr.mm6509e2

17. Khanal S, Bahl S, Sharifuzzaman M, Dhongde D, Pattamadilok S, Reef S, et al. Progress toward Rubella and Congenital Rubella syndrome control South-East Asia Region, 2000-2016. MMWR Morb Mortal Wkly Rep. (2018) 67:602-6. doi: 10.15585/mmwr.mm6721a3

18. O'Connor P, Jankovic D, Zimmerman L, Ben Mamou M, Reef S. Progress toward Rubella elimination - World Health Organization European Region, 2005-2019. MMWR Morb Mortal Wkly Rep. (2021) 70:833-9. doi: 10.15585/mmwr.mm7023a1

19. Barboza-Argüello M, Umaña-Solís LM, Azofeifa A, Valencia D, Flores $\mathrm{AL}$, Rodríguez-Aguilar $\mathrm{S}$, et al. Neural tube defects in Costa Rica, 1987-2012: origins and development of birth defect surveillance and folic acid fortification. Matern Child Health J. (2015) 19:583-90. doi: 10.1007/s10995-014-1542-8

20. Atta CA, Fiest KM, Frolkis AD, Jette N, Pringsheim T, St Germaine-Smith C, et al. Global birth prevalence of spina bifida by folic acid fortification status: a systematic review and meta-analysis. Am J Public Health. (2016) 106:e24-34. doi: 10.2105/AJPH.2015.302902a

21. Murphy ME, Westmark CJ. Folic acid fortification and neural tube defect risk: analysis of the food fortification initiative dataset. Nutrients. (2020) 12:247. doi: 10.3390/nu12010247

22. Meaney FJ, Miller LA, FASSNet Team. A comparison of fetal alcohol syndrome surveillance network and birth defects surveillance methodology in determining prevalence rates of fetal alcohol syndrome. Birth Defects Res A Clin Mol Teratol. (2003) 67:819-22. doi: 10.1002/bdra. 10122 
23. Fox DJ, Druschel CM. Estimating prevalence of fetal alcohol syndrome (FAS): effectiveness of a passive birth defects registry system. Birth Defects Res A Clin Mol Teratol. (2003) 67:604-8. doi: 10.1002/bdra.10108

24. Hymbaugh K, Miller LA, Druschel CM, Podvin DW, Meaney FJ, Boyle CA, et al. A multiple source methodology for the surveillance of fetal alcohol syndrome-The Fetal Alcohol Syndrome Surveillance Network (FASSNet). Teratology. (2002) 66(Suppl. 1):S41-9. doi: 10.1002/tera.90010

25. Moberg DP, Bowser J, Burd L, Elliott AJ, Punyko J, Wilton G, et al. Fetal alcohol syndrome surveillance: age of syndrome manifestation in case ascertainment. Birth Defects Res A Clin Mol Teratol. (2014) 100:663-9. doi: 10.1002/bdra.23245

26. O'Leary LA, Ortiz L, Montgomery A, Fox DJ, Cunniff C, Ruttenber M, et al. Methods for surveillance of fetal alcohol syndrome: the Fetal Alcohol Syndrome Surveillance Network II (FASSNetII) - Arizona, Colorado, New York, 2009 - 2014. Birth Defects Res A Clin Mol Teratol. (2015) 103:196-202. doi: $10.1002 /$ bdra. 23335

27. Montgomery A, Miller L. Using the Colorado birth defects monitoring program to connect families with services for children with special needs. Teratology. (2001) 64(Suppl. 1):S42-6. doi: 10.1002/tera.1098

28. Farel AM, Meyer RE, Hicken M, Edmonds LD. Registry to referral: using birth defects registries to refer infants and toddlers for early intervention services. Birth Defects Res A Clin Mol Teratol. (2003) 67:647-50. doi: 10.1002/bdra.10116

29. Lin AE, Rasmussen SA, Scheuerle A, Stevenson RE. Clinical geneticists in birth defects surveillance and epidemiology research programs: past, present and future roles. Birth Defects Res A Clin Mol Teratol. (2009) 85:69-75. doi: 10.1002/bdra.20548

30. Kirby RS, Browne ML. Putting birth defects surveillance data to action. Birth Defects Res. (2021) 113:115-6. doi: 10.1002/bdr2.1861

31. Parker SE, Mai CT, Canfield MA, Rickard R, Wang Y, Meyer RE, et al. Updated National Birth Prevalence estimates for selected birth defects in the United States, 2004-2006. Birth Defects Res A Clin Mol Teratol. (2010) 88:1008-16. doi: 10.1002/bdra.20735

32. Botto LD, Robert-Gnansia E, Siffel C, Harris J, Borman B, Mastroiacovo P. Fostering international collaboration in birth defects research and prevention: a perspective from the International Clearinghouse for Birth Defects Surveillance and Research. Am J Public Health. (2006) 96:774-80. doi: 10.2105/AJPH.2004.057760

33. Yazdy MM, Autry AR, Honein MA, Frias JL. Use of special education services by children with orofacial clefts. Birth Defects Res A Clin Mol Teratol. (2008) 82:147-54. doi: 10.1002/bdra.20433

34. Mai CT, Cassell CH, Meyer RE, Isenburg J, Canfield MA, Rickard R, et al. Birth defects data from population-based birth defects surveillance programs in the United States, 2007 to 2011: highlighting orofacial clefts. Birth Defects Res A Clin Mol Teratol. (2014) 100:895-904. doi: 10.1002/bdra.23329

35. Mitani AA, Haneuse S. Small data challenges of studying rare diseases. JAMA Netw Open. (2020) 3:e201965. doi: 10.1001/jamanetworkopen.2020. 1965

36. Zarante I, Hurtado-Villa P, Walani SR, Kancherla V, López Camelo J, Giugliani $\mathrm{R}$, et al. A consensus statement on birth defects surveillance, prevention, and care in Latin America and the Caribbean. Rev Panam Salud Publica. (2019) 43:e2. doi: 10.26633/RPSP. 2019.2

37. Sales Luiz Vianna F, de Oliveira MZ, Sanseverino MT, Morelo EF, de Lyra Rabello Neto D, Lopez-Camelo J, et al. Pharmacoepidemiology and thalidomide embryopathy surveillance in Brazil. Reprod Toxicol. (2015) 53:63-7. doi: 10.1016/j.reprotox.2015.03.007

38. Kowalski TW, Gomes JDA, Garcia GBC, Fraga LR, Paixao-Cortes VR, Recamonde-Mendoza M, et al. CRL4-Cereblon complex in Thalidomide Embryopathy: a translational investigation. Sci Rep. (2020) 10:851. doi: 10.1038/s41598-020-57512-x

39. WHO, CDC, ICBDSR. Birth Defects Surveillance Training: Facilitator's Guide. Geneva: World Health Organization (2015). p. 162. Available online at: https://www.who.int/publications/i/item/9789241549288 (accessed September 29, 2021).

40. Centers for Disease Control and Prevention. Birth Defects Surveillance Course Overview. (2021). Available online at: https://www.cdc.gov/ncbddd/birthd efects/surveillancemanual/facilitators-guide/course-overview.html (accessed September 23, 2021).
41. International Clearinghouse for Birth Defects Surveillance and Research. Online Self-paced Course on Birth Defect Surveillance and Prevention. (2021). Available online at: http://www.icbdsr.org/online-self-paced-course-onbirth-defect-surveillance-and-prevention/ (accessed September 23, 2021).

42. Training Programs in Epidemiology and Public Health Interventions Network. Zika Virus and Birth Defects. (2021). Available online at: https://www.tephinet.org/zika-virus-and-birth-defects-english (accessed September 23, 2021).

43. Cassell CH, Grosse SD, Kirby RS. Leveraging birth defects surveillance data for health services research. Birth Defects Res A Clin Mol Teratol. (2014) 100:815-21. doi: 10.1002/bdra.23330

44. Copeland GE, Kirby RS. Using birth defects registry data to evaluate infant and childhood mortality associated with birth defects: an alternative to traditional mortality assessment using underlying cause of death statistics. Birth Defects Res A Clin Mol Teratol. (2007) 79:792-7. doi: 10.1002/bdra.20391

45. Mai CT, Kirby RS, Correa A, Rosenberg D, Petros M, Fagen MC. Public health practice of population-based birth defects surveillance programs in the United States. J Public Health Manag Pract. (2016) 22:E1-8. doi: 10.1097/PHH.0000000000000221

46. Ely DM, Driscoll AK. Infant mortality in the United States, 2018: data from the period linked birth/infant death file. Natl Vital Stat Rep. (2020) 69:1-18.

47. Peterson C, Dawson A, Grosse SD, Riehle-Colarusso T, Olney RS, Tanner JP, et al. Hospitalizations, costs, and mortality among infants with critical congenital heart disease: how important is timely detection? Birth Defects Res A Clin Mol Teratol. (2013) 97:664-72. doi: 10.1002/bdra.23165

48. Bell JC, Baynam G, Bergman J, Bermejo-Sánchez E, Botto LD, Canfield MA, et al. Survival of infants born with esophageal atresia among 24 international birth defects surveillance programs. Birth Defects Res. (2021) 113:945-57. doi: 10.1002/bdr2.1891

49. Bakker MK, Kancherla V, Canfield MA, Bermejo-Sanchez E, Cragan JD, Dastgiri S, et al. Analysis of mortality among neonates and children with spina bifida: an international registry-based study, 2001-2012. Paediatr Perinat Epidemiol. (2019) 33:436-48. doi: 10.1111/ppe.12589

50. Politis MD, Bermejo-Sánchez E, Canfield MA, Contiero P, Cragan JD, Dastgiri S, et al. Prevalence and mortality in children with congenital diaphragmatic hernia: a multicountry study. Ann Epidemiol. (2021) 56:619.e3. doi: 10.1016/j.annepidem.2020.11.007

51. Nembhard WN, Bergman JEH, Politis MD, Arteaga-Vázquez J, BermejoSánchez E, Canfield MA, et al. A multi-country study of prevalence and early childhood mortality among children with omphalocele. Birth Defects Res. (2020) 112:1787-801. doi: 10.1002/bdr2.1822

52. Poletta FA, Gili JA, Castilla EE. Latin American Collaborative Study of Congenital Malformations (ECLAMC): a model for health collaborative studies. Public Health Genomics. (2014) 17:61-7. doi: 10.1159/000356568

53. Flores A, Valencia D, Sekkarie A, Hillard CL, Williams J, Groisman B, et al. Building capacity for birth defects surveillance in Africa: implementation of an intermediate birth defects surveillance workshop. J Glob Health Perspect. (2015) 2015:1.

54. Mumpe-Mwanja D, Barlow-Mosha L, Williamson D, Valencia D, Serunjogi R, Kakande A, et al. A hospital-based birth defects surveillance system in Kampala, Uganda. BMC Pregnancy Childb. (2019) 19:372. doi: $10.1186 / \mathrm{s} 12884-019-2542-\mathrm{x}$

55. Lowry RB, Bedard T. Birth defect registries: the vagaries of management- the British Columbia and Alberta case histories. J Registry Manag. (2013) 40:98103.

56. Larrandaburu M, Vianna FSL, Griot K, Queijo C, Monzón C, Ugarte C, et al. Rare diseases in Uruguay: focus on infants with abnormal newborn screening. JIEMS. (2019) 7:e20190002. doi: 10.1590/2326-4594-jiems-2019-0002

57. Mütze U, Garbade SF, Gramer G, Lindner M, Freisinger P, Grünert SC, et al. Long-term outcomes of individuals with metabolic diseases identified through newborn screening. Pediatrics. (2020) 146:e20200444. doi: $10.1542 /$ peds.2020-0444

58. González-Irazabal Y, Hernandez de Abajo G, Martínez-Morillo E. Identifying and overcoming barriers to harmonize newborn screening programs through consensus strategies. Crit Rev Clin Lab Sci. (2021) 58:29-48. doi: $10.1080 / 10408363.2020 .1781778$

59. Argudo-Ramírez A, Martín-Nalda A, Marín-Soria JL, López-Galera RM, Pajares-García S, González de Aledo-Castillo JM, et al. First universal newborn 
screening program for severe combined immunodeficiency in Europe. Twoyears' experience in Catalonia (Spain). Front Immunol. (2019) 10:2406. doi: 10.3389 /fimmu.2019.02406

60. Kamenov K, Chadha S. Methodological quality of clinical guidelines for universal newborn hearing screening. Dev Med Child Neurol. (2021) 63:16-21. doi: $10.1111 / \mathrm{dmcn} .14694$

61. da Cunha LP, Cavalcante Costa MAA, de Miranda HA II, Reis Guimarães J, Aihara T, Ludwig CA, et al. Comparison between wide-field digital imaging system and the red reflex test for universal newborn eye screening in Brazil. Acta Ophthalmol. (2021) 99:e1198-205. doi: 10.1111/aos.14759

62. Ferrier C, Dhombres F, Khoshnood B, Randrianaivo H, Perthus I, Guilbaut L, et al. Trends in resource use and effectiveness of ultrasound detection of fetal structural anomalies in France: a multiple registry-based study. BMJ Open. (2019) 9:e025482. doi: 10.1136/bmjopen-2018-025482

63. Ferrier C, Khoshnood B, Dhombres F, Randrianaivo H, Perthus I, Jouannic $\mathrm{JM}$, et al. Cost and outcomes of the ultrasound screening program for birth defects over time: a population-based study in France. BMJ Open. (2020) 10:e036566. doi: 10.1136/bmjopen-2019-036566

64. Gyurkovits Z, Sohár G, Baricsa A, Németh G, Orvos H, Dubs B. Early detection of developmental dysplasia of hip by ultrasound. Hip Int. (2021) 31:424-9. doi: 10.1177/1120700019879687

65. Kilsdonk I, Witbreuk M, Van Der Woude HJ. Ultrasound of the neonatal hip as a screening tool for DDH: how to screen and differences in screening programs between European countries. J Ultrason. (2021) 21:e14753. doi: $10.15557 / \mathrm{JoU} .2021 .0024$

66. Suard C, Flori A, Paoli F, Loundou A, Fouilloux V, Sigaudy S, et al. Accuracy of prenatal screening for congenital heart disease in population: a retrospective study in Southern France. PLoS ONE. (2020) 15:e0239476. doi: 10.1371 /journal.pone. 0239476

67. Jullien S. Newborn pulse oximetry screening for critical congenital heart defects. BMC Pediatr. (2021) 21:305. doi: 10.1186/s12887-021-02520-7

68. Sun M, Ma A, Li F, Cheng K, Zhang M, Yang H, et al. Sensitivity and specificity of red reflex test in newborn eye screening. J Pediatr. (2016) 179:192-6.e4. doi: 10.1016/j.jpeds.2016.08.048
69. Kanji A, Khoza-Shangase K, Moroe N. Newborn hearing screening protocols and their outcomes: a systematic review. Int J Pediatr Otorhinolaryngol. (2018) 115:104-9. doi: 10.1016/j.ijporl.2018.09.026

70. Botto LD, Mastroiacovo P. Triple surveillance: a proposal for an integrated strategy to support and accelerate birth defect prevention. Ann N Y Acad Sci. (2018) 1414:126-36. doi: 10.1111/nyas.13600

71. Romeo AN, Leedom V, Nance A, Chambers C, Contreras D, Lupo PJ, et al. Promoting collaborations to improve birth defects surveillance, research, and prevention: a joint editorial from the National Birth Defects Prevention Network and the Organization of Teratology Information Specialists. Birth Defects Res. (2021) 113:117-22. doi: 10.1002/bdr2.1852

72. Ludorf KL, Salemi JL, Kirby RS, Tanner JP, Agopian AJ. Perspectives on challenges and opportunities for birth defects surveillance programs during and after the COVID-19 era. Birth Defects Res. (2020) 112:1039-42. doi: 10.1002/bdr2.1710

Conflict of Interest: The authors declare that the research was conducted in the absence of any commercial or financial relationships that could be construed as a potential conflict of interest.

Publisher's Note: All claims expressed in this article are solely those of the authors and do not necessarily represent those of their affiliated organizations, or those of the publisher, the editors and the reviewers. Any product that may be evaluated in this article, or claim that may be made by its manufacturer, is not guaranteed or endorsed by the publisher.

Copyright $\odot 2021$ Melo, Sanseverino, Schmalfuss and Larrandaburu. This is an open-access article distributed under the terms of the Creative Commons Attribution License (CC BY). The use, distribution or reproduction in other forums is permitted, provided the original author(s) and the copyright owner(s) are credited and that the original publication in this journal is cited, in accordance with accepted academic practice. No use, distribution or reproduction is permitted which does not comply with these terms. 